\title{
Use of Autonomy-Supportive and Controlling Behaviors: A Mixed-Methods Investigation in NCAA Division I Football
}

\author{
Tucker Readdy \\ University of Wyoming \\ Johannes Raabe \\ University of Tennessee
}

\begin{abstract}
Grounded in self-determination theory (Deci \& Ryan, 1985, 2000), the coachathlete relationship model (Mageau \& Vallerand, 2003) suggests that coaches can positively affect athletes' basic psychological needs satisfaction and motivation through autonomy-supporting behavior. Yet, little research has explored coaches' objective use of autonomy support or the personal and contextual demands associated with such interactions. The current study used a mixed-methods design to describe coaches' utilization, perceived benefits of, and challenges to the provision of autonomy support during an NCAA football season. Participants were nine assistant coaches at a Division I university. Each coach was live-coded at one practice each week for the duration of the 12-game schedule. At midseason, participants received a report of the percentage of interactions in teaching, organization, cheering, autonomy support, and controlling behaviors, as well as recommendations for improvement. Coach-level RM-ANOVA results demonstrated a variety in the number and magnitude of statistically significant changes in four of the five behavior categories; effect sizes ranged from small to large. Postseason interviews suggested coaches were attuned to the results and suggestions of the report, but that both personal and social influences (e.g., knowledge of SDT, competition with other coaches) as well as contextual factors (e.g., time constraints of practice, competition results) were also important in influencing behavior change. Thus, autonomy support is a viable and valuable pursuit in the context of collegiate athletics, but further development of practical, effective strategies is needed.
\end{abstract}

Keywords: motivation, self-determination, mixed methods research, coaching

Nick Saban, head coach of five teams that have won the National Collegiate Athletics Association (NCAA) championship in football, opens his book How good

Readdy is with the Dept. of Kinesiology and Health, University of Wyoming, Laramie, Wyoming. Raabe is with the Dept. of Kinesiology, Recreation, and Sport Studies, Knoxville, Tennessee. Address author correspondence to Tucker Readdy at tucker.readdy@uwyo.edu. 
do you want to be? A champion's tips on how to lead and succeed with the thought that, "Becoming a champion is not an easy process..." (p. 3) and later intimates that one of the keys to the 2003 national championship was the attitude that, "...we would not be outworked any day of the year" (Saban, 2005, p. 5). This statement highlights that the time and effort that collegiate football players and coaches - truly, all collegiate athletes and coaches - invest in their pursuit of success on a nearly daily basis is immense. It is no surprise, then, that better understanding motivation, or the "why" of human behavior, in the sport domain remains a popular topic in various areas of study, including sport psychology and coach education. Why all the grueling practices? Why all the off-season workouts? Why all of the nonphysical preparation? Why any of it when, as Saban suggests, none of it is an easy process?

While there are many viable approaches to describing the complex nature of motivation, self-determination theory (SDT; Deci \& Ryan, 1985, 2000) holds considerable promise in providing a comprehensive understanding of the precursors to, moderators of, and outcomes related to motivated behavior in the sport setting. This potential comes, in part, because SDT takes into account the possible varying effects of categorically distinct types of motivation (i.e., amotivation, extrinsic motivation, and intrinsic motivation) rather than assuming that more motivation is inherently better (Teixeira, Carraca, Markland, Silva, \& Ryan, 2012). In addition, it suggests numerous practical strategies for coaches (i.e., fostering the basic psychological needs of autonomy, competence, and relatedness through using autonomy-supportive behaviors and minimizing controlling behaviors) that are effective for enhancing the motivation of athletes across a variety of contexts. The rapid proliferation of SDT research in the sport context includes investigations of how coach autonomy support is associated with well-being in elite athletes (e.g., Adie, Duda, \& Ntoumanis, 2012), motivation in college and Olympic athletes (e.g., Hollembeak \& Amorose, 2005), and even athletes' injury recovery (Podlog \& Dionigi, 2010). Such work demonstrates not only the utility of SDT, but also the importance of fostering an optimal motivational climate in elite sport settings.

Despite the body of evidence supporting the premises of SDT in the sport domain, existing studies (e.g., Adie et al., 2012; Hollembeak \& Amorose 2005) often measure athletes' perceptions of autonomy support and controlling interactions from their coaches. As such, there is a dearth of research that objectively documents the use of these behaviors by coaches (e.g., Webster, Hunt, \& LaFleche, 2013), particularly at the elite level. In addition, there is a need for a better understanding of the personal and contextual factors that contribute to coaches being autonomysupportive or controlling. As such, one purpose of the current investigation was to quantify NCAA Division I football coaches' utilization of autonomy-supportive and controlling behaviors at practice over the duration of a season. A complimentary aim was to assess whether significant changes in such interactions would occur following a report of how often a coach engaged in those behaviors during the first half of the season. The final goal was to qualitatively document individual, social and contextual influences on coaches' use of autonomy-supportive behaviors.

\section{Theory and Literature Review}

According to Deci and Ryan (2000), SDT differentiates itself from other theories of motivation in suggesting that, "... a full understanding of not only goal-directed 
behavior, but also of psychological development and well-being, cannot be achieved without addressing the needs that give goals their psychological potence [sic]..." (p. 228). As such, one main premise of SDT is that optimal motivation is more likely to occur when an individual's three basic psychological needs of autonomy, competence, and relatedness are satisfied (Deci \& Ryan, 2000). People are apt to feel autonomous when they have choice to engage in behaviors that are in agreement with their values. Similarly, competence is achieved when individuals feel they interact successfully in a specific environment. Finally, relatedness can be experienced when there is a meaningful connection to and reciprocation from important others in that same context (Deci \& Ryan, 2000). The sport environment is a compelling context for examining basic psychological need satisfaction, in that it can provide immediate and powerful competence-feedback (e.g., winning or losing a competition, verbal interactions with coaches), support or diminish an athlete's perception of autonomy (e.g., strict adherence to specific training schedules and organizational policies), and either foster or diminish relatedness (e.g., teammates may be perceived as competition for a starting position, coaches may have athletecentered or controlling interpersonal styles; Vallerand \& Losier, 1999). Due to this environmental variability, it is important that coaches, who "...can have a crucial impact on athletes' motivation..." (Vallerand \& Losier, 1999, p. 150), make the satisfaction of basic psychological needs a priority.

Such a focus on basic psychological need fulfillment is necessary because a second assumption of SDT is that the satisfaction or thwarting of these needs is directly related to the type of motivational regulation people experience (Deci \& Ryan, 2000). Intrinsic motivation is the desire to engage in an activity for the inherent pleasure it provides; this is contrasted with amotivation, where individuals have no motivation to participate in a behavior. Between these two forms of motivation is a continuum of extrinsic regulations from external (an activity is done to gain a reward or avoid a punishment), to introjected (an action is done to experience positive emotions such as pride or prevent negative emotions such as guilt), to identified (a behavior is pursued for the instrumental purpose of reaching another, more valued goal), to integrated (an activity is seen as congruent with a person's values and identity; Deci \& Ryan, 2000). Research in the sport setting has demonstrated that the experience of intrinsic, integrated, and identified motivation (collectively known as self-determined motivation) is associated with positive psychological experiences (e.g., athlete positive emotions and satisfaction; Blanchard, Amiot, Perreault, Vallerand, \& Provencher, 2009) and behavioral engagement (e.g., athlete performance; Gillet, Berjot, \& Gobance, 2009). Again, sport presents a complex milieu where all of these motivational regulations can be observed and influenced by a variety of factors, including tangible rewards for success as well as interactions between coach and athlete (Vallerand \& Losier, 1999).

Mageau and Vallerand's (2003) coach-athlete relationship model is one framework that has guided some research into the application of SDT to the sport context. In sum, within this model, behaviors of coaches and the basic psychological need fulfillment of the athletes are linked. Centrally positioned is the use of seven specific classes of autonomy-supporting behaviors: (a) providing choice within specific rules and limits, (b) providing rationale for tasks and limits, (c) acknowledging the athlete's feelings and perspectives, (d) providing athletes with opportunities for initiative taking and independent work, (e) providing noncontrolling competence 
feedback, (f) avoiding controlling behaviors (including criticisms and rewards for interesting tasks), and (g) preventing ego-involvement in athletes (Mageau \& Vallerand, 2003). When these behaviors occur in conjunction with coaches' provision of instruction and structure in the sport environment (used to foster competence) as well as demonstration of social involvement and support (used to improve relatedness), an athlete's motivation should be more self-determined and, hopefully, optimized. Oppositely, coaches can also engage in controlling behaviors that pressure athletes to think and act in certain ways through guilt induction, the use of explicit criticism, and provision of extrinsic rewards for goal achievement (Mageau \& Vallerand, 2003; Soenens, Vansteenkiste, Sierens, Dochy \& Goossens, 2012). Both autonomy-supportive and controlling behaviors are thought to influence all three psychological needs, suggesting that a powerful and pragmatic means to support self-determined motivation in athletes is to assist coaches in both effectively increasing the former and decreasing the latter as they can occur independently of one another.

In multiple studies (e.g., Adie et al., 2012; Blanchard et al., 2009; Hollembeak \& Amorose, 2005), researchers have documented player perceptions of autonomysupportive versus controlling coaching styles, with the general consensus that higher perceptions of autonomy support and lower perceptions of controlling behavior are significantly linked to basic psychological need satisfaction and motivational regulation. However, little is actually known about the use of these behaviors, especially in the competitive sport environment. For example, Stebbings, Taylor, and Spray (2011) offer the following:

It is imperative, therefore, that researchers identify and determine coaches' use of these interpersonal styles [autonomy-supportive versus controlling], so that an autonomy supportive style can be promoted and controlling coaching styles diminished. To date, however, there is a dearth of research addressing this line of inquiry. (p. 256)

In two studies conducted in the context of physical education classes, researchers used live coding of teacher-student interactions to objectively measure the amount of autonomy support instructors provided. For example, Sarrazin, Tessier, Pelletier, Trouilloud, and Chanal (2006) documented that autonomy-support was only $4.6 \%$ of the communication between teachers and students while controlling behaviors were $37.2 \%$ of the interactions; quite similarly, Sarrazin, Trouilloud, Tessier, Chanal, and Bois (2005) concluded that 95\% of exchanges between instructors and pupils were done in a controlling manner. Despite some methodological limitations (i.e., Sarrazin et al., 2005, collapsed all behaviors into mutually exclusive categories of autonomy-supportive and controlling which dismisses neutral interactions), the findings from Sarrazin et al. (2006) and Sarrazin et al. (2005) potentially signal poor motivational outcomes for the students in those classes due to the limited use of autonomy-supportive behaviors.

To date, few researchers have explored whether similar patterns of interactions happen in the sport context. In fact, in only one study was live coding used to quantify high school boys soccer coaches' use of various categories of autonomy support during both practices and games; recorded behaviors included offering choice, praising or encouraging the athlete, providing rationale for a task, and soliciting input from players (Webster, et al., 2013). Results were reported in rates per minutes of each behavior category, making them difficult to compare with Sarrazin 
et al. (2005) or Sarrazin et al. (2006). While praise and encouragement occurred most frequently (between .27 and .82 interactions per minute), offering choice to athletes happened at the lowest rate (between .01 and .04 interactions per minute); the latter values seem consistent with the low percentages of autonomy support reported in physical education settings. Qualitative interviews of coaches in the Webster et al. (2013) study suggested that while the participants were not trained in providing autonomy support, they believed the specific behaviors measured in the study were important to helping athletes develop ownership in the team as well as improve as competitors. Interestingly, there was little difference between the use of autonomy support by more successful coaches (career winning percentage above $70 \%$ ) as compared with less successful coaches (career winning percentage below $50 \%$ ). This seems to imply that a coach's interpersonal style may be a more important contextual factor than objective competitive outcomes in influencing the use of autonomy support; more importantly, some evidence suggests that interpersonal communication patterns (e.g., coaching style) are malleable and can be positively affected by interventions (Mageau \& Vallerand, 2003). Still, both factors warrant further empirical consideration in their relationship to the use of autonomy-supportive interactions from coaches.

Clearly, understanding a coach's use of autonomy-supportive behaviors is a complex task, as there are various personal, social, and contextual factors involved (Mageau \& Vallerand, 2003). For example, whether a coach is informed about SDT could contribute to these behaviors being displayed; similarly, a coach may know what autonomy-supporting interactions are, but their use may be restricted by pressure to succeed, the result of the previous week's game, time and personal stressors, or other factors that may escalate as the competitive level becomes more elite. For example, Stebbings et al. (2011) demonstrated that coaches' perceptions of their own basic psychological need satisfaction were positively related to their perceived engagement in autonomy support and negatively related to perceived engagement in controlling behavior. Yet, there is also research to suggest that coaches tend not to be self-aware in the coaching environment (Smith \& Smoll, 2006), a factor that can lead to a discrepancy between the perceived and actual use of various coaching behaviors. As such, it is important for coaches to be aware of their use of autonomy-supporting as well as controlling behaviors and understand the personal, social, and contextual factors that lead to their use. By becoming more informed about such dynamics, coaches may improve their use of interactions that foster self-determined motivation despite contextual influences that could make such behavior challenging.

In sum, the observation provided by Stebbings et al. (2011) regarding the limited amount of existing research into the use of autonomy-supportive and controlling coaching styles is consistent with Mageau and Vallerand's (2003) advocacy for more studies focused on confirming the theoretical tenants of the coach-athlete relationship model, especially in the sport context. Thus, the present research sought to fulfill the following three objectives: (a) objectively quantify NCAA Division I football coaches' utilization of autonomy-supportive and controlling behaviors at practice through live behavioral coding over the course of a 12-game season, (b) determine whether significant changes in autonomysupportive and controlling interactions occurred following a report that included the frequency a coach engaged in those behaviors as well as strategies to enhance 
autonomy-supportive interactions, and (c) qualitatively describe personal, social and contextual factors that enhanced or diminished the utilization of autonomy support by the participants.

\section{Methods}

\section{Research Paradigm}

While mixed-methods approaches are challenging to effectively design and communicate due to their intricate epistemological and ontological considerations (Smith, Sparkes, Phoenix, \& Kirkby, 2012), such a design was purposefully chosen for this study as it helped the researchers navigate some of the environmental challenges that were inherent in the research (e.g., lack of opportunity to interrupt practice for purposes of inquiry and clarification, participant burden in answering questionnaires following each practice). Pairing quantitative and qualitative components within the same study can help to "reveal a greater complexity and multidimensionality of experience than expected" (Eklund, Jeffery, Doersek, \& Cho, 2011, p. 287). These outcomes are often achieved through both initiation (creation of innovative insight into the research questions) and complementarity (emphasizing and augmenting the results from one methodology with the other; Moran, Matthews, \& Kirby, 2011). For example, observing a change in coaching behavior would be relatively uninformative without exploring why such variation happened. Using the experiences and retrospective thoughts of the participants allowed for both initiation and complementarity to occur in a meaningful way, thereby enhancing the potential recommendations and practical applications derived from the research.

Demonstrating the efficacy and value of the mixed-methods approach, particularly the qualitative component, was guided by suggestions provided by Sparkes and Smith (2009), Tracy (2010), and Weed (2009). Sparkes and Smith (2009) support a relativist as opposed to a criteriological approach, where, "Various criteria, therefore, in list form may act as a starting point [emphasis in original] for judging a certain kind of inquiry, but these may not apply on all occasions" (p. 495). That starting point was the consideration of six of Tracy's (2010) eight "big tent" criteria for qualitative research of value: worthy topic, rich rigor, credibility, resonance, significant contribution, and meaningful coherence. Unlike the quantitative portion of the study that represented a postpositivist paradigm, the qualitative analysis used an interpretivist paradigm with a constructionist epistemology (the knower and known are inseparable in the qualitative component) and internal ontology (multiple, constructed realities are created within and between individual participant's responses as well as the quantitative and qualitative results; Weed, 2009). As such, the qualitative data helped to develop an alternative, untold perspective to the quantitative numbers, creating complementarity between the two sources (Moran et al., 2011). Adding observations from the primary author's field notes contributed to the credibility of the work through crystallization between multiple sources of data (often referred to as triangulation by other qualitative scholars; Tracy, 2010). In addition, quantitative data were collected through daily presence at practice throughout the season, adding to the rich rigor represented in the study by increasing the time spent in the field and the richness of the data (Tracy, 2010). 


\section{Research Setting, Participants, and Data Sources}

This study was conducted at a university in the Rocky Mountain region of the United States that maintains Division I Football Bowl Subdivision (FBS) standing in the NCAA, in part by supporting eight women's and seven men's varsity sports. Collectively, these teams greatly contribute to the visibility of, connection to, and sense of pride in the university for people throughout the state. The university's football coaching staff was selected for participation based on an existing sport psychology consulting relationship between the first author and the head coach; this connection was vital, as it provided for the access necessary for the intensive data collection used in the research. Specifically, the consultant provided educational resources (i.e., presentations, readings) to the organization with the intended outcome of enhancing competitive success, especially in light of the team experiencing a losing season the year before the study after participating in a bowl game the previous year. The first author was not monetarily compensated for his efforts on behalf of the team, including the work represented the current research, while the second author was a graduate student and research assistant helping the first author as part of his degree requirements. In addition, to protect the confidentiality of the assistant coaches, the head coach was not provided with results of the study. As such, potential conflicts of interest were minimized to the extent possible.

A total of nine assistant football coaches (the entire staff other than the head coach) agreed to participate in the study. The average age of this cohort was 36.4 years, while their average experience in coaching was 12.9 years (range 3-29 years), which included experiences at the high school, NCAA Divisions I, II, and III levels. It is important to note that seven of the nine coaches engaged in a workshop eight months before when the current study was conducted. Information about SDT (Deci \& Ryan, 1985, 2000), Mageau and Vallerand's (2003) coachathlete relationship model, and strategies for the use of autonomy support was shared during the workshop. While this workshop was not part of the intervention for this research and was delivered nearly one year before the start of the study, it is imperative to disclose this contextual factor as part of the coaches' professional development regarding the theoretical concepts that formed the framework for the present investigation.

Given the information provided above, the current research is best described as a case study, most specifically a collective case study where, "...the researcher again selects one issue or concern but also selects multiple case studies to illustrate the issue" (Cresswell, Hanson, Clark, \& Morales, 2007). The "issue" was the use of autonomy support and controlling behaviors by the participants in the study, while the data analyses (described in subsequent sections) allowed for the presentation of information from individual coaches rather than summarizing the results across the entire group. The primary sources of data were systematic behavioral observations of the participants and qualitative interviews (explained in subsequent sections). In addition, the lead author kept extensive field notes while attending practices. These records were focused on perceived personal, social, and contextual factors that might influence coaches' use of autonomy support and controlling behavior, which allowed for more informed follow-up questions during the interviews and a more detailed perspective when analyzing the qualitative data. 


\section{Procedures}

Approval for the study was obtained from the university's Institutional Review Board. Based on previous literature (i.e., Sarrazin et al., 2006) and through a pilot study conducted with the football team's strength and conditioning staff, a theoretically-grounded list of context-specific coaching behaviors was established related to teaching, organizing, and questions, each of which could be done in an autonomy-supportive, neutral, or controlling manner (see Table 1). In addition, various other interactions were coded (see Table 1); the four classes of controlling behaviors were derived from the Controlling Coach Behaviors Scale (Bartholomew,

\section{Table 1 Specific Behaviors, Higher-Order Interaction Categories, and Descriptions}

\begin{tabular}{|c|c|}
\hline $\begin{array}{l}\text { Specific Behavior and } \\
\text { Higher-order Interaction } \\
\text { Categories }\end{array}$ & Description \\
\hline Organizational, $\mathrm{C}^{\mathrm{c}, \mathrm{d}}$ & Athlete must, has to, or ought to do something \\
\hline Organizational, $\mathrm{N}^{\mathrm{d}}$ & Organizational comment not $\mathrm{C}$ or AS \\
\hline Organizational, AS a,d & $\begin{array}{l}\text { Athlete is provided choice in some organizational } \\
\text { aspect of practice }\end{array}$ \\
\hline Teaching, $\mathrm{C}^{\mathrm{c}, \mathrm{e}}$ & Technical or tactical directive that imposes a skill \\
\hline Teaching, $\mathrm{N}^{\mathrm{e}}$ & Technical/tactical comment not $\mathrm{C}$ or AS \\
\hline Teaching, AS ${ }^{\mathrm{a}, \mathrm{e}}$ & $\begin{array}{l}\text { Suggestions encourage athletes to take initiative or } \\
\text { solve problems independently }\end{array}$ \\
\hline Technical $(\mathrm{N})+$ Praise $^{\mathrm{b}, \mathrm{e}}$ & Technical, $\mathrm{N}$ followed by Praise \\
\hline Questions, $\mathrm{C}^{\mathrm{c}, \mathrm{e}}$ & Directives posed as a question \\
\hline Questions, $\mathrm{N}^{\mathrm{e}}$ & Question not C or AS \\
\hline Questions, AS ${ }^{\mathrm{a}, \mathrm{e}}$ & Questions that pose a true choice to the athlete \\
\hline Praises ${ }^{\mathrm{b}, \mathrm{e}}$ & Verbal approval of past effort \\
\hline Encouragements ${ }^{b}$ & Statement used to increase future effort \\
\hline Praise + Encouragement ${ }^{b, e}$ & Praise followed by Encouragement \\
\hline Perspective-taking a & $\begin{array}{l}\text { Empathic statement that reflects an understanding of the } \\
\text { athlete's perspective (football-related) }\end{array}$ \\
\hline Relatedness $^{\text {a }}$ & Positive nonfootball related comments \\
\hline Controlling use of rewards ${ }^{c}$ & Coach uses reward to make athlete train harder \\
\hline Negative conditional regard ${ }^{c}$ & $\begin{array}{l}\text { Coach less friendly/supportive if athlete not training } \\
\text { well }\end{array}$ \\
\hline Intimidations \& Criticisms ${ }^{c}$ & Coach threatens punishment, embarrasses athlete \\
\hline Excessive Personal Control $^{\mathrm{c}}$ & Coach tries to control athlete's free time \\
\hline
\end{tabular}

Note: $\mathrm{C}=$ Controlling; $\mathrm{N}=$ Neutral, $\mathrm{AS}=$ Autonomy-supportive; ${ }^{\mathrm{a}}=$ autonomy support; ${ }^{\mathrm{b}}=$ cheering; ${ }^{\mathrm{c}}=$ controlling behavior; ${ }^{\mathrm{d}}=$ organization; ${ }^{\mathrm{e}}=$ teaching

Categories of behaviors based on Sarrazin et al. (2006), pilot study, and Bartholomew et al. (2010) 
Ntoumanis, \& Thogersen-Ntoumani, 2010). For purposes of statistical analysis and the coaches' reports, all recorded behaviors were condensed into non-mutually exclusive categories that included teaching, organization, cheering, autonomy support, and controlling interactions (see Table 1 for the categories that each specific behavior was factored into). Each coach was observed in person and frequencycoded for the duration of one practice per week, with sessions varying in duration from 75 min to $140 \mathrm{~min}$. Given that there was a different emphasis each Tuesday, Wednesday, and Thursday of practice, the day of the week each participant was coded rotated throughout the duration of the 12-week season such that each specific day was coded four times for each coach. All practices consisted of a mixture of individual, unit (offense/defense), and full-team drills.

In the portions of practice that were accessible (greater than $80 \%$ of coachathlete contact time), verbal exchanges with players were live coded by one of four trained research assistants, all of whom were familiar with SDT; three members of the group were involved with the pilot study and had accumulated at least 25 hours of live-coding experience before the start of the study, while the fourth was trained for 10 hours by the lead author. Training for the live observation system followed the five phases described by van der Mars (1989): orientation to the coding system, learning the behavior categories, using the coding form correctly, initial coding practice, and live observation practice. Interrater reliability between the lead author and each coder was assessed once each week, and the average Cohen's Kappa during that time was 91.6 (range from 82 to 94.7), indicating acceptable reliability (van der Mars, 1989). While other forms of observation were considered (i.e., video- and audio-recording practices), the head coach would not approve this higher perceived level of participant burden. Finally, the principal investigator attended all practices with the exception of one week.

Following the midpoint of the season (Game 6), each coach received an individualized report of the average number of behaviors in each category, the total number of behaviors, and the percentage of overall behaviors in organizing, teaching, cheering, autonomy support, and controlling interactions; the averages across all coaches were also provided as a point of comparison. The decision to present each class of interactions as a percentage of overall behavior (rather than as a rate per minute) was made because durations of each practice session changed on a weekly basis throughout the season. In addition, the report contained practical suggestions for improvement and the principal investigator spent approximately 15 min presenting the data and recommendations to each coach individually. Sample strategies included maximizing teaching and autonomy-supportive behaviors during specific periods of practice (i.e., stretching, walkthrough portions), reframing neutral statements as autonomy-supportive (e.g., changing "Throw to the outside receiver on that play" to "Which receiver is your best option on that play?" to allow for independent thinking), and understanding how to provide technical corrections without making personally hurtful statements.

At the end of the season, a second report was developed for each participant that contained the change in percentage of interactions spent in each behavioral category. The average percentage of interactions in each behavioral class across all coaches was also provided, again as a point of reference. The first author met with 6 of the 9 participants for approximately 30 minutes each to discuss the report as well as observations and questions related to intrapersonal, interpersonal, 
and contextual factors that might explain the change in coaching behaviors; the remaining three coaches had moved to other universities before they could be interviewed. These semistructured conversations were not audio-recorded, also a condition of approval for the study from the head coach; rather, extensive notes were taken throughout the interviews. The report was provided in advance of the interviews to allow participants an opportunity to reflect on how their coaching behavior changed (or did not) over the course of the season. Three specific questions formed the foundation for the interviews: (a) "From your perspective, why did your coaching behavior change this season?"; (b) "What was easy or difficult about using autonomy-support?"; and (c) "Was there any benefit to you being in the research study?" Appropriate follow-up inquires were used to help participants explain their initial responses and elucidate deeper meanings to their responses.

\section{Quantitative Analyses}

For each coach, to determine whether there was a significant change in the percentage of interactions within each class of coaching behavior from before to after the review of the coaching report, a Repeated Measures Multivariate Analysis of Variance (RM-ANOVA) was conducted. The dichotomous variable "before/after report" was used as the fixed factor, while the proportions of behaviors related to teaching, organizing, cheering, autonomy support, and controlling interactions were the dependent variables. Using the standard Bonferroni adjustment, the alpha level used to determine statistical significance was $p<.01(p=.05$ divided by five dependent variables). To help determine the practical significance of any statistically significant changes across behavior categories, Cohen's $d$ (Cohen, 1988) was calculated; the larger of the two standard deviations was used in the denominator to produce a more conservative estimate that reduces the likelihood of overstating the practical significance of any changes seen. Cohen's $d<0.2$ was considered a small effect, between 0.2 and 0.8 a medium effect, and greater than 0.8 a large effect (Cohen, 1988).

\section{Qualitative Analyses}

Analysis of general interview statements used a focused, thematic coding approach that generally followed the six-step process of becoming acquainted with the data, forming initial codes, identifying themes, refining themes, defining themes, and generating the report (Braun \& Clarke, 2006). Both authors reviewed the notes taken by the first author during each of the interviews; these were read within each interview (i.e., all of the responses from a single participant) and across interview questions (i.e., the answer to a single question for all six coaches) multiple times. Second, each author independently developed initial codes (i.e., identifying "interesting features of the data in a systematic fashion across the entire data set"; Braun $\&$ Clarke, 2006, p. 87) for the data and subsequently met to explicitly agree upon the name and content of each code as well as discuss potential themes and subthemes. Third, each author individually reanalyzed the data using the formalized codes, with specific attention given to whether subthemes and themes truly captured the nature of the entire data set. Given the relatively small number of codes, there was $96 \%$ agreement between the authors and discrepancies were resolved through discussion 
until agreement was established. Finally, after minor modifications (i.e., reducing the number of subthemes and agreeing upon specific language for the themes), the subthemes and themes were officially named as reported in the Results section. The continuous communication between the two authors throughout the data analysis helped with the credibility of the study through peer debriefing (or triangulation between researchers; Tracy, 2010). To further contribute to the credibility of the qualitative analysis through member reflection (often referred to as member checks; Tracy, 2010), summaries and direct quotes from the interviews and qualitative themes from the analysis were provided to each coach with an opportunity to offer feedback; no responses were received.

\section{Results}

\section{Descriptive Statistics}

To briefly summarize the variation in teaching, organizational, cheering, autonomy support, and controlling interactions for each coach from before to after distribution and discussion of coaching reports, Table 2 provides the percent change, statistical significance, and Cohen's $d$ for each behavioral category. For a more detailed presentation, Tables 3-7 depict the means and standard deviations for each coach within the five behavioral categories both before and following the reports. Across the entire season, there were an average of 266 behaviors recorded per coach per practice $(S D=67.8)$, with the highest average being 400 and the lowest average being 180 . During the portion of the season before reports were produced, coaches spent the largest percentage of time in organizational behaviors $(M=40.8 \%)$, followed by a relatively equal percentage of time in teaching interactions $(M=22.1 \%)$ and cheering $(M=26.1 \%)$. The percentage of time in both autonomy-support $(M=$ $5.2 \%)$ and controlling behaviors $(M=5.8 \%)$ were comparably smaller. Following the reports, participants spent considerably less time in organization $(M=27.1 \%)$ with increases in teaching $(M=29.0 \%)$, cheering $(M=30.2 \%)$, and autonomy support $(M=8.1 \%)$; the percentage of controlling interactions remained relatively constant $(M=5.6 \%)$. However, given that group-level examination of behavior change can mask individual-level differences that occurred, inferential statistics were conducted for all coaches individually.

\section{Inferential Statistics}

Results of the RM-ANOVA (see Tables 3-7) revealed a more nuanced profile of how each coach changed his percentage of behaviors in teaching, organization, cheering, autonomy support, and controlling interactions. It should be noted that the intended effect of the reports was to increase the percentage of interactions dedicated to teaching and autonomy support, while decreasing the percentage of controlling behaviors; logically, such alterations would be achieved through a reduction in organization and potentially cheering interactions. Five of the nine participants demonstrated a statistically significant change in at least one of the behavior categories, with Coach 8 decreasing in organization $(-29.9 \%)$ while increasing in cheering $(+28.2 \%)$ and autonomy support $(+8.0 \%, p$-values $<.01)$. The greatest number of statistically significant changes was seen within organizational 


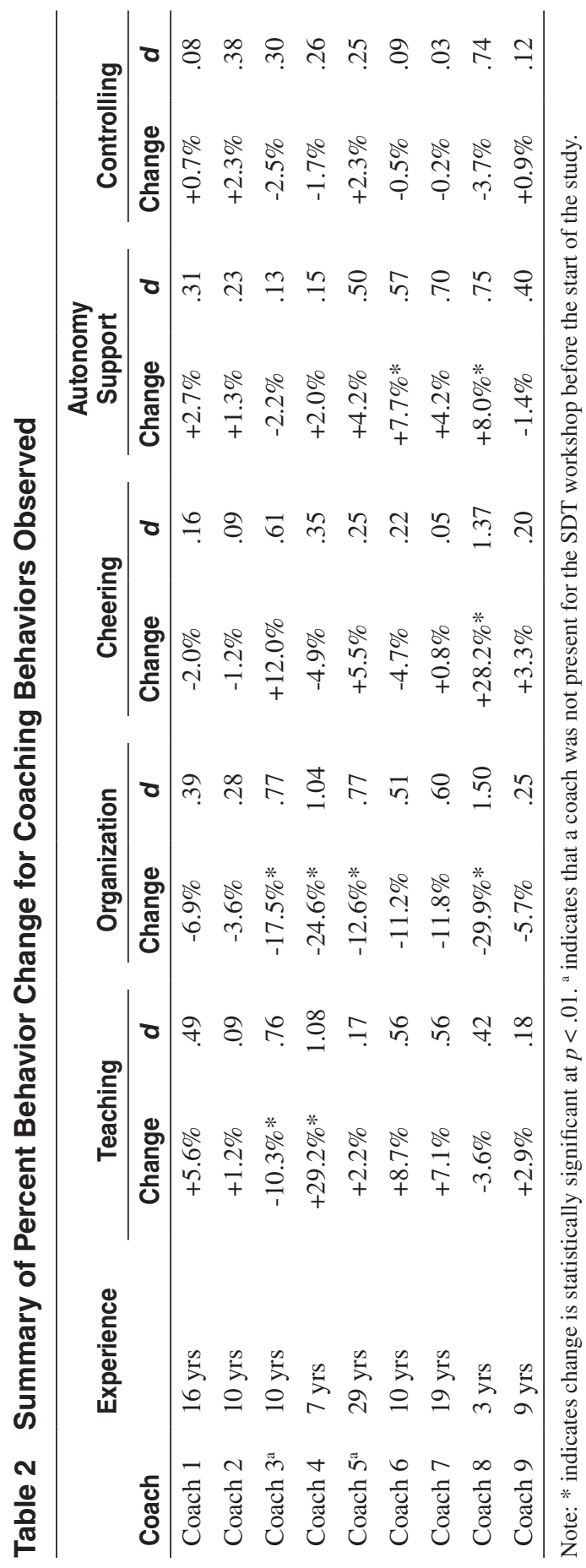

JIS Vol. 9, No. 2, 2016 


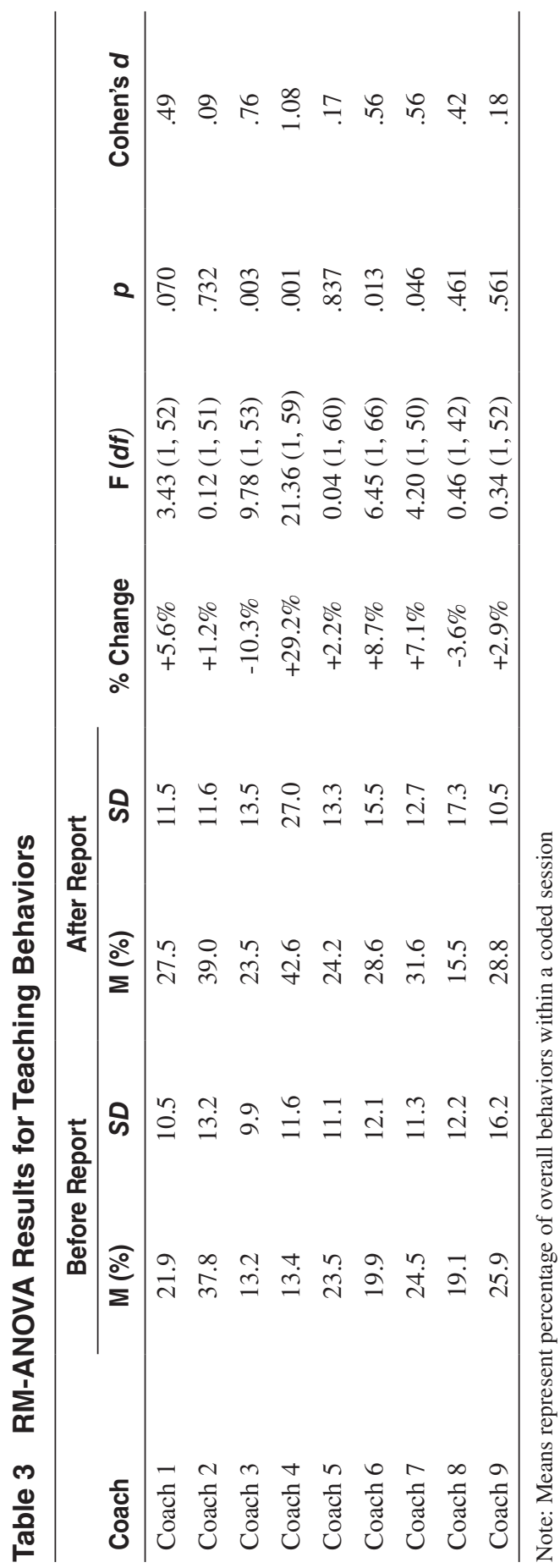




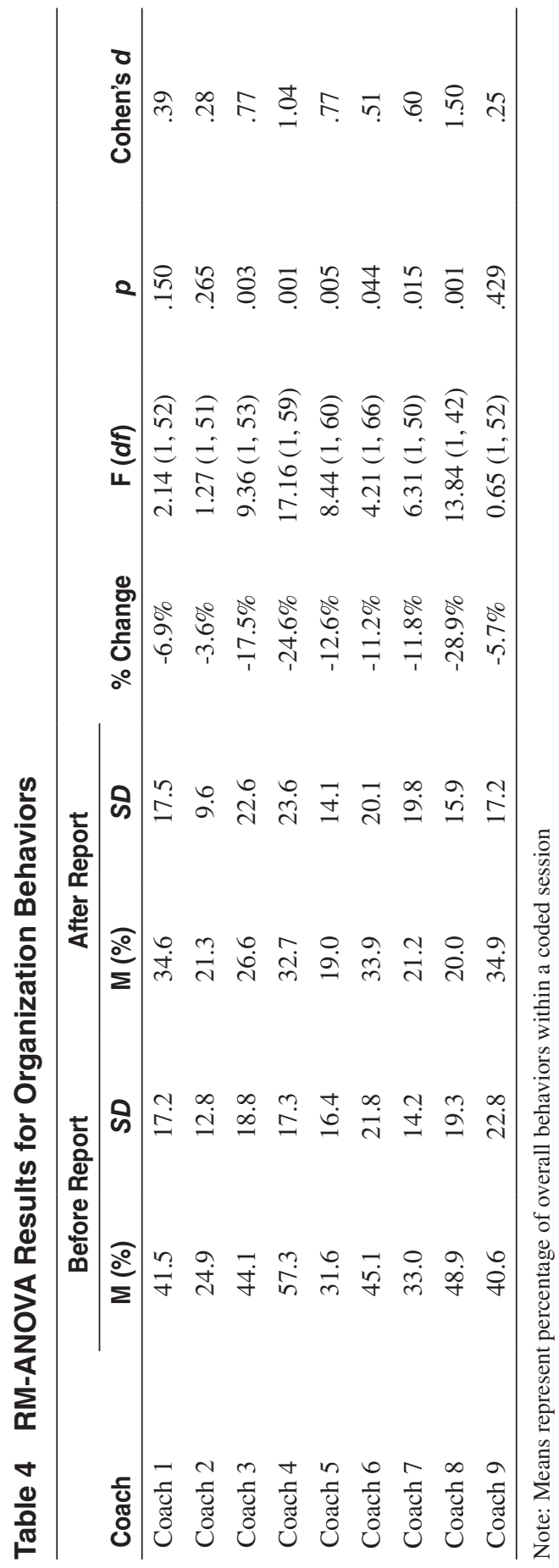

JIS Vol. 9, No. 2, 2016 


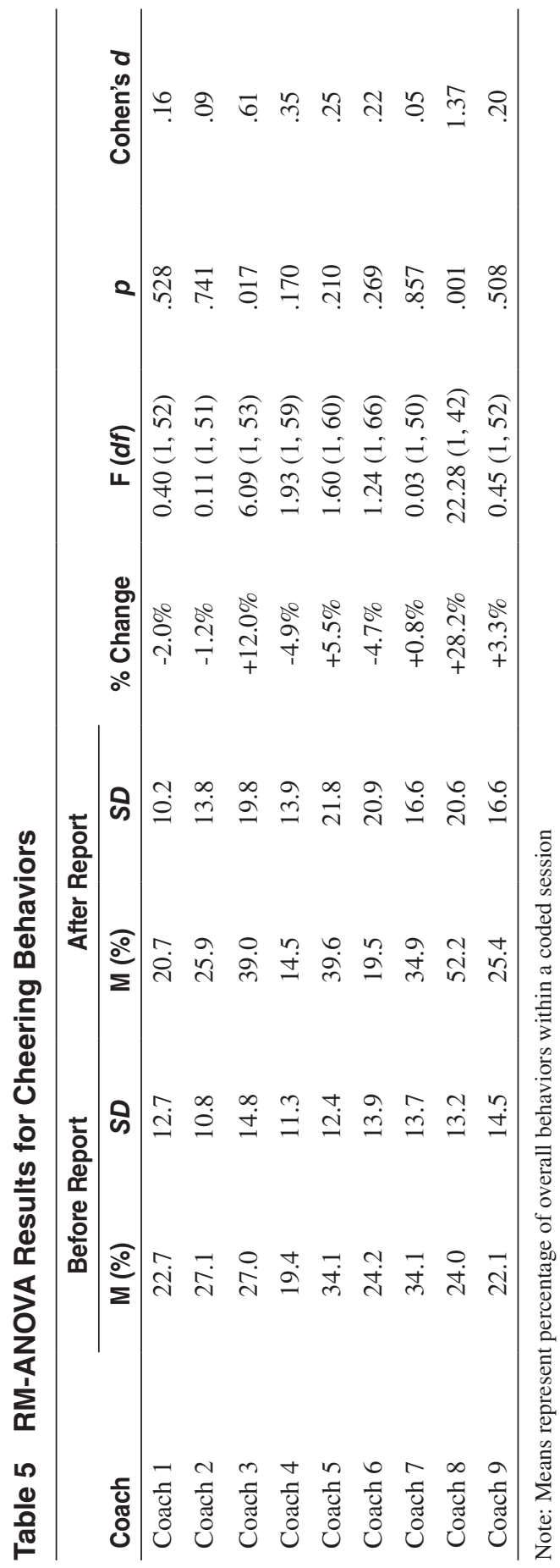




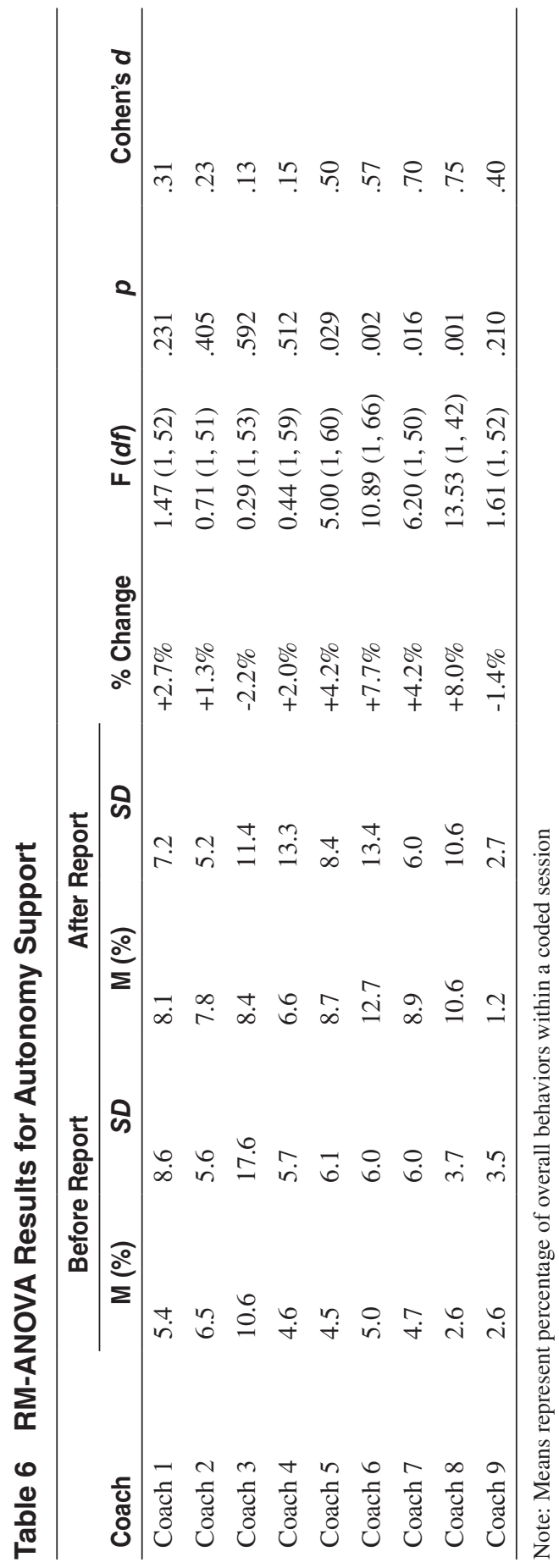

JIS Vol. 9, No. 2, 2016 


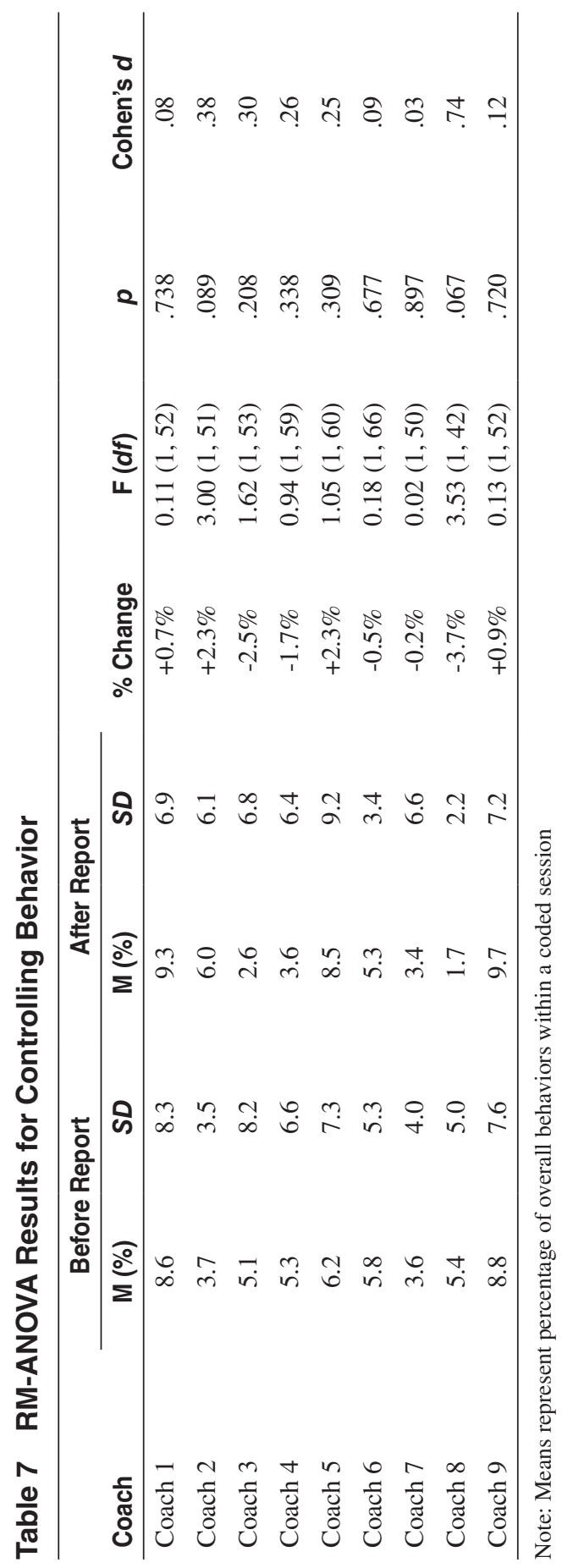


behaviors, with four of the nine participants decreasing their percentages $(-29.9 \%$, $-24.6 \%,-17.5 \%$, and $-12.6 \%$; $p$-values $<.01)$. Similarly, two of the nine coaches increased their autonomy support $(+8.0 \%$ and $+7.7 \%$; $p$-values $<.01)$ while another two changed their teaching interactions $(+29.2 \%$ and $-10.3 \%$; $p$-values $<.01)$. It is important to note that these two individuals shared coaching responsibilities for the same position; as such, following the report which suggested a different distribution of tasks for this pair of participants, a decrease in teaching behavior for one coach was necessary for an increase in teaching for the other. Finally, none of the coaches accomplished a statistically significant decrease in their controlling behaviors.

In addition to consideration of the statistical significance of behavior change, the practical significance indicated by the various Cohen's $d$ 's demonstrated that a majority of effect sizes were moderate-to-large for all interaction categories: teaching ( 6 of the 9 were $>0.2$; average $d=.48$ ), organizational (all 9 were $>0.2$; average $d=.68$ ), cheering ( 5 of the 9 were $>0.2$, average $d=.37$ ), autonomy support ( 7 of the 9 were $>0.2$, average $d=.42$ ), and controlling interactions ( 5 of the 9 were $>.20$; average $d=.25$ ). Four of the nine coaches achieved medium-to-large changes in four of the five behavior categories, while three did the same in three categories and one (Coach 2) did so in just two categories. Coach 8 was the only participant to have moderate-to-large variations in all five categories ( $d$ range $=$ $.42-1.50$, average $d=.96)$.

\section{Interviews}

As previously noted, the interviews were designed to gather coaches' perspectives on why their behavior had changed over the season, the ease or difficulty of providing autonomy support, and the benefit of the research study. The credibility and resonance of the following descriptions are enhanced through thick description where possible, multivocality, and attention to genuine and aesthetic presentations of the participants' feedback that show rather than tell the results (Tracy, 2010).

Causes for Changes in Behavior. The potential causes for changes in coaches' behavior were classified into three themes: (a) the research study; (b) personal and social characteristics; and (c) contextual factors. With respect to the effects of the study itself, most coaches reflected that the initial report (provided following the sixth game of the season) was part of the reason specific behaviors may have changed. For example, Coach 9 who had the highest percentage of controlling behaviors immediately asked for more strategies to reduce such occurrences; despite this interest, his controlling interactions actually increased from $8.8 \%$ to $9.7 \%$. Another interviewee (Coach 8) who expressed considerable interest in autonomy support similarly asked for more recommendations to improve that aspect of his interactions with the student-athletes on the team and did so, increasing such behaviors from $2.6 \%$ to $10.6 \%$. This impact of the research study was balanced on a more microscopic basis by coaches initially being attuned to the presence of the trained behavioral coders at practice. As one coach shared, "It's on your mind... when I see your guy, it helps. Not on command, but you put in a teaching point with a negative comment, you know?" Another participant supported the consistent impact of the program, sharing that the ideas related to autonomy support were becoming part of the structural emphasis of the organization. As such, coaches were attuned, both specifically and globally, to the 
information and suggestions contained in the reports provided to them. However, such attention did not automatically lead to the intended results.

In addition, certain personal and social characteristics made the results of the coaching reports more salient for participants. At the forefront of those considerations was coaching experience, both overall and with the current team. Practice observations and field notes suggested that often these worked in contradictory fashion; coaches with more overall experience (i.e., Coach 1, Coach 5) were less likely to explicitly attempt to change their behavior, but that was in part balanced by a perceived need to fit into the organizational dynamics of the current team. Some individuals believed the research study was an excellent opportunity to develop their coaching skills (discussed in more detail below), a factor that was also skewed toward people who had less coaching experience. The influence of competition between coaches cannot be discounted either, as during the interviews, participants tended to ask where they were in relation to their counterparts. From a social perspective, there were two position groups where two coaches were responsible instead of one (Coaches 3 and 4; Coaches 6 and 7). This division of labor was seen as a potential factor helping with behavior changes, in that they could attempt to balance interactions across the organizational and teaching categories; Coach 3 and 4 were effective with this change, while Coaches 6 and 7 modified their behavior in the intended direction but did not achieve statistical significance.

Despite these positive reflections on the possible impact of the research study and how it manifested at the personal and social level, every coach was quick to note that the context of the season could not be disregarded. Aside from simply winning or losing, Coach 3 shared that "...the first half of the season is just 'go, go, go!' with physical implementation of the scheme. The second half, you have injuries, the team is different, people are more comfortable, so it lends itself to teaching more." Interestingly, Coach 3 actually increased his cheering behavior and decreased his teaching interactions following the report. Specific to the outcome of games, many participants reflected on the nature of the season; as Coach 5 noted, aside from a couple of games "... as the season went on, there was simply less to be negative about. We were playing well." Of note is that winning and losing was not a blanket influence on the types of coaching behaviors. Sometimes, coaches did not perceive their specific group to have played well. Other times, it was simply one player, as Coach 9 shared much about "the power of just one negative guy" and how that influenced the interactions he engaged in throughout one practice; interestingly, this was the same participant who, as previously noted, showed interest in reducing controlling interactions but did not actually do so. In sum, there was recognition of many potential causes for coaches' changes in behavior at individual and structural levels, elements that worked synergistically or divergently depending on the factors unique to the coach.

Ease and Difficulty of Providing Autonomy Support. Similar to the focused themes that arose in describing the potential causes for changes in coaches' behavior, those that developed regarding the ease and difficulty of providing autonomy support reflected both personal and contextual considerations. Specifically, these were conceptual understanding of autonomy-support (personal) and the time-sensitive practice environment (contextual). Before the initial workshop on SDT and autonomy support, only two of the nine participants (Coach 2 and 
Coach 6) had any meaningful exposure to ideas such as intrinsic or extrinsic motivation, controlling behaviors, etc. Despite this brief exposure to theoretical concepts of interest, most of the interviewees expressed that they were still unclear of some of the principles. Coach 4, who achieved marked increases in teaching and decreases in organizational interactions, intimated that it was a “...partly-conscious, developmental process. I am getting more experience, I think I am getting better, but it's tough." Not all coaches gave conscious effort to understanding the principles of autonomy support; specifically, Coach 5, who had joined the team following the workshop offered, "I hear a few things about it, I see you around, but that's all I know." Clearly, a major source of difficulty in using autonomy support is developing a meaningful understanding of the more abstract ideas as well as practicing the immediate, context-specific applications. Notably, none of the coaches mentioned it was easy to be autonomy-supportive.

Another dimension that likely contributed to the perceived difficulty of being autonomy-supportive was the fast-paced nature of the practice setting. Every segment of practice was scripted to the minute, and the next portion began regardless of whether coaches had finished what they were doing in the previous portion. As such, directive statements were perceived as time-efficient, both because the coaches were not thinking about how to rephrase a sentence to be autonomy-supportive and because the instruction was simply grammatically shorter. In addition, participants believed that players did not take as much time to process and respond to nonautonomy-supportive directions; in that respect, Coach 7 shared, "You've seen how much time we have out there. If we have them think or make choices, that can mean a big difference in how many reps [repetitions of a play] we get." Here, the advantage of having two coaches for a position was apparent (Coaches 3 and 4, Coaches 6 and 7), as one could focus on engaging in autonomy-support or teaching while the other could handle the organizational aspects of practice. Provision of choice was clearly the behavior most coaches reflected on, but giving rationale to student-athletes was also perceived as time-consuming. As such, even coaches who believed they could implement various aspects of autonomy-support did not sense that the practice environment was particularly conducive to it.

Benefits of the Research Study. Whether at the level of autonomy support or the level of general coaching behaviors, all coaches recognized that being part of the current study was beneficial to them. For example, Coach 7 reflected very specifically on how, "Now I can teach through player mistakes, rather than yelling through them." His perceptions were accurate, in that he did increase his percentage of teaching interactions but did not reduce his controlling interactions. Another interviewee was more general in sharing, "This is forcing me to become a better coach. If this doesn't work out, I'll land somewhere else, and be better." Some even acknowledged the potential generalization for autonomy support into contexts that were not specifically addressed in the study (e.g., prepractice meetings, staff meetings for coaches), even suggesting that the study could be augmented to look at coach-coach interactions. Very powerfully, Coach 2 shared that, "For this to work, you need guys who don't need to be in control at all times. I am now more comfortable with that." However, when the same interviewee was asked if that could truly be embraced in the context of college football, his response was a long, ironic laugh. 


\section{Discussion}

The beneficial effects of perceived autonomy support on basic psychological needs satisfaction and self-determined motivation have been demonstrated across multiple sports and at various age levels (e.g., Adie et al., 2012; Hollembeak \& Amorose, 2005; Kipp \& Weiss, 2013). Yet, objective documentation of the provision of autonomy support and description of the factors that contribute to or constrain the use of such behaviors have not yet been adequately explored in the competitive sport context. Thus, the current study addressed a worthy topic that is relevant, timely, and interesting (Tracy, 2010) while uniquely adding to the SDT and autonomy support literature in elite sport environments. The current research used a mixed-method design to examine NCAA Division I football coaches' use of organizational, teaching, cheering, autonomy support, and controlling behaviors at practice over the duration of a 12-game season, as well as elucidate some of the contextual influences on the delivery of autonomy support. The study also investigated whether a report documenting participants' engagement in these behaviors along with recommendations for improvement could serve as an effective intervention to help maximize autonomy support and other optimal coaching interactions with student-athletes.

In line with previous research in the physical education context (Sarrazin et al., 2005; Sarrazin et al., 2006) and high school soccer (Webster et al., 2013), the use of autonomy support in the present research was very low (on average, less than one in every 10 interactions). While the methodologies differed and the collegiate athletic context diverges significantly from that of the elementary school physical education or high school sport environment, it is compelling to consider the limited number of interactions that are autonomy-supportive and potential reasons for this scarcity should be explored. One finding that emerged from the interviews is the lack of education about the specifics of autonomy support as well as the complexities of applying those principles in a practical setting, even for coaches in an elite performance context. This finding would not have been evident without the complementarity and initiation provided by mixed-methods research and further supports such designs. Even for a group of coaches who were at least minimally educated about such ideas and were embedded in an organization that was perceived to endorse such principles, mastery of the techniques was not immediate. As such, one recommendation stemming from this research that has been echoed across other studies (e.g., Kipp \& Weiss, 2013) is that coaches need to be better versed, both theoretically and practically, in how to enhance athlete motivation through the application of frameworks such as SDT; in addition, those who have been provided such information also need to endorse the importance of autonomy support and practice it on a regular basis. At least for the participants in this study, such education was understood as beneficial, even if execution of the behaviors was not ideal (as in the case of Coach 9 who wanted to decrease controlling behaviors but was not successful in doing so).

Importantly, the current research extended previous work exploring the description of autonomy support in multiple ways. First, it sought to illustrate multiple personal, social and contextual factors that were related to the use of autonomy support, a unique contribution to the literature; in contrast, Sarrazin et al.'s (2006) focus was primarily teacher expectancies of student motivation. Beyond the need 
for education and belief in the importance of autonomy support, the coaches in this study clearly recognized factors outside of their control (i.e., the structure and time-sensitive nature of practice generally controlled by the head coach, the outcome of previous competitions, perceived support from or competition with other coaches) that also influenced their ability to be autonomy-supportive. Mageau and Vallerand's (2003) coach-athlete relationship model recognizes the influence of a coach's personal style as well as the coaching context on a coach's engagement in autonomy support. Here, such factors were sometimes congruent (e.g., the latter part of the season, regardless of a team's record, may be more conducive to certain coaching behaviors) and other times discrepant (e.g., some coaches may not want to change their personal style, even if it is valued by the organization. Too few studies have focused on the influence of such factors on the provision of autonomy support in elite athletic contexts (Mageau \& Vallerand, 2003), and the current research is one, albeit small, step in that direction. As such, the current study supports the need for further work with more frequent, in-depth exploration of coaches' personal styles, their efficacy for engaging in autonomy support, and the context in which they engage in their craft.

Secondly, this study expanded on previous research (e.g., Sarrazin et al., 2005; Sarrazin et al., 2006) by using multiple categories of coaching behavior as opposed to simply autonomy support versus controlling interactions; the complexity of the behavioral coding system and the longitudinal nature of the data collection should not be overlooked as a strength of the current undertaking. Consistent with Webster et al. (2013), this finer level of distinction between types of interactions with student-athletes was beneficial in capturing a more holistic representation of coach engagement with players over an entire season. Based on such information, comprehensive feedback was provided to each participant in the study, and the interviews suggested that such evidence was seen as a positive factor in helping coaches optimize their behavior throughout the season. Results from the quantitative analyses showed statistically and practically significant improvement in all of the behavioral categories. It should also not be dismissed that only two of the nine coaches improved their autonomy support in a statistically significant way; this lends credence to the participants' reflections on the difficulty of engaging in such behaviors, particularly due to the time-sensitive nature of practice and the perceived complexity of making directive or controlling statements into autonomy-supportive interactions. Moreover, controlling interactions did not decrease significantly, providing further evidence that the two often coexist in the same instructional environment (e.g., Sarrazin et al., 2006). Still, the present research extends existing literature by demonstrating that a brief, relatively simple intervention (i.e., providing suggestions of how to structure interactions with athletes so that they are autonomy-supportive) can be both objectively and subjectively effective. The mixed-method approach was again of benefit in both of these respects, as the complementarity allowed for greater detail and explanation than would have been possible with either a quantitative or qualitative methodology alone.

While such changes in coaching behavior (or lack thereof) are certainly not solely due to the report provided or the monitoring of coaching behavior throughout practices, the potential impact of the feedback cannot be overlooked. One possible limitation of the present research is that it did not adopt multiple baselines across coaches or across behaviors; as such, future research with more detailed 
methodologies examining whether more frequent assessment and discussion of coaching is associated with even greater changes in behavior is warranted, as are studies across multiple seasons to determine if such changes are maintained over time. Comparisons of various types of sports (e.g., individual, coacting, and team) and different team sizes also seem justified, as the dynamics specific to a football team are not necessarily generalized to other competitive contexts. Perhaps most importantly, player perceptions of autonomy support were not examined in this study and determining whether student-athletes are sensitive to changes in their coaches' behaviors is important. Successful objective enhancement of autonomy support is not as meaningful if it does not have an impact on the basic psychological needs, motivation, and cognitive, affective, as well as behavioral outcomes of its recipients. Moreover, while the percentage of autonomy support was low, its presence is still important as research in the education domain (Curran, Hill, \& Niemiec, 2013) suggests that such behavior may actually moderate the relationship between structure provided by the teacher (or coach) and basic psychological need satisfaction. Thus, the presence of autonomy support may be a prerequisite for other important behaviors (i.e., teaching, organization) to be perceived positively, and future studies should explore this dynamic in the elite sport context.

Certainly, the current study is not without other limitations. First, while the trained observers did their best to remain inconspicuous throughout the study, some participants mentioned their presence (and that of the first author) as a reminder to engage in more optimal behaviors; thus, the possibility that the Hawthorne effect contributed to some of the results cannot be discounted. However, given that the head coach did not consent to audio- or video-recording and the need for the trained observers to be close enough to the coaches to hear their interactions with the athletes, this participant reactivity was challenging to overcome. Similarly, despite the best efforts of the research team to collect reliable and valid data, such constraints could potentially affect the accuracy of the results. Second, practice is only one setting where autonomy support and effective coaching behavior can be used, as are games, meetings, etc. Similarly, nonverbal communications were not taken into account. Thus, it is quite possible that the overall autonomy support in this study was much higher (or lower), but that the context it was measured in did not allow for a comprehensive representation. Third, while the coding instrument was designed specifically for this study and appropriate interrater reliability was documented, research to further demonstrate the validity of the instrument is warranted. Finally, it must be noted that none of the study participants were candid enough to mention the influence of the head coach in either a positive or negative manner. The fact that the top person in the organization granted permission for the research to be conducted could be interpreted as evidence for his belief in the importance of optimizing coaching behavior generally and, more specifically, through developing autonomy support within the staff. As a result, it is quite possible that the observed behavior change and comments provided in the interview were implicitly or explicitly shaped by the subordinate status of the assistant coaches to the head coach, another important contextual factor to consider. While such limitations are important to contemplate in determining the overall value of the research, they should not overshadow the contribution the study makes to the understanding of autonomy support in elite sport contexts as well as to the body of knowledge focused on coaching behavior. 


\section{Conclusions}

Based on the findings of the present research, it is evident that the likelihood of autonomy support being used is influenced by a multitude of factors at the personal, social, and contextual levels, some of which this study elucidated in a meaningful mixed-method approach that incorporated the lived experiences of coaches attempting to use these behaviors. It should also be considered that very basic interventions, in this case the provision of an objective report of coaching behaviors and strategies for maximizing optimal interactions, can be subjectively perceived as an asset to coaches and sport teams even if the objective results are mixed. On a methodological level, the current work judiciously balanced the mix of quantitative and qualitative findings to develop a synergistic meaning beyond what was possible in adopting a singular approach. As such, the study demonstrated meaningful coherence (linking literature, research questions, results, and analysis in a coherent, influential manner) and hoped to make a significant contribution to the existing literature in both a theoretical and practical fashion (Tracy, 2010). As many of the interviewees in the study suggested, such work, is of benefit, as it can only help them become better coaches and, hopefully, have a positive influence on the lives of the athletes they are involved with. As Nick Saban (2005) reminds us, "Champions are rare. Everybody has some chance, some opportunity to change and improve..." (p. 214) and those of us in the field of sport psychology and coach education can assist all coaches in their pursuit of that improvement and success.

\section{References}

Adie, J.W., Duda, J.L., \& Ntoumanis, N. (2012). Perceived coach-autonomy support, basic need satisfaction, and the well- and ill-being of elite youth soccer players: A longitudinal investigation. Psychology of Sport and Exercise, 13, 51-59. doi:10.1016/j. psychsport.2011.07.008

Bartholomew, K., Ntoumanis, N., \& Thogersen-Ntoumani, C. (2010). The controlling interpersonal style in a coaching context: Development and initial validation of a psychometric scale. Journal of Sport \& Exercise Psychology, 32, 193-216. PubMed doi:10.1123/jsep.32.2.193

Blanchard, C.M., Amiot, C.E., Perreault, S., Vallereand, R.J., \& Provencher, P. (2009). Cohesiveness, coach's interpersonal style and psychological needs: Their effects on self-determination and athletes' subjective well-being. Psychology of Sport and Exercise, 10, 545-551. doi:10.1016/j.psychsport.2009.02.005

Braun, V., \& Clarke, V. (2006). Using thematic analysis in psychology. Qualitative Research in Psychology, 3, 77-101. doi:10.1191/1478088706qp063oa

Cohen, J. (1988). Statistical power analysis for the behavioral sciences. Hillsdale, NJ: Erlbaum.

Cresswell, J.W., Hanson, W.E., Plano Clark, V.L., \& Morales, A. (2007). Qualitative research designs: Selection and implementation. The Counseling Psychologist, 35, 236-264. doi:10.1177/0011000006287390

Curran, T., Hill, A.P., \& Niemiec, C.P. (2013). A conditional process model of children's behavioral engagement and behavioral disaffection in sport based on self-determination theory. Journal of Sport \& Exercise Psychology, 35, 30-43. PubMed doi:10.1123/jsep.35.1.30

Deci, E.L., \& Ryan, R.M. (1985). Intrinsic motivation and self-determination in human behavior. New York: Plenum Press. doi:10.1007/978-1-4899-2271-7 
Deci, E.L., \& Ryan, R.M. (2000). The "what" and "why" of goal pursuits: Human needs and the self-determination theory of behavior. Psychological Inquiry, 11, 227-268. doi:10.1207/S15327965PLI1104_01

Eklund, R.C., Jeffery, K.A., Doersek, U., \& Cho, S. (2011). Reflections on qualitative research in sport psychology. Qualitative Research in Sport, Exercise and Health, 3, 285-290. doi:10.1080/2159676X.2011.607183

Gillet, N., Berjot, S., \& Gobance, L. (2009). A motivational model of performance in the sport domain. European Journal of Sport Science, 9, 151-158. doi:10.1080/17461390902736793

Hollembeak, J., \& Amorose, A.J. (2005). Perceived coaching behaviors and college athletes' intrinsic motivation: A test of self-determination theory. Journal of Applied Sport Psychology, 17, 20-36. doi:10.1080/10413200590907540

Kipp, L.E., \& Weiss, M.R. (2013). Social influences, psychological need satisfaction, and well-being among female adolescent gymnasts. Sport, Exercise, and Performance Psychology, 2, 62-75. doi:10.1037/a0030236

Mageau, G.A., \& Vallerand, R.J. (2003). The coach-athlete relationship: A motivational model. Journal of Sports Sciences, 21, 883-904. PubMed doi:10.1080/0264041031000140374

Moran, A.P., Matthews, J.J., \& Kirby, K. (2011). Whatever happened to the third paradigm? Exploring mixed methods research in sport and exercise psychology. Qualitative Research in Sport, Exercise and Health, 3, 362-369. doi:10.1080/21596 76X.2011.607843

Podlog, L., \& Dionigi, R. (2010). Coach strategies for addressing psychological challenges during the return to sport from injury. Journal of Sports Sciences, 28, 1197-1208. PubMed doi:10.1080/02640414.2010.487873

Saban, N. (2005). How good do you want to be? A champion's tips on how to lead and succeed. New York: Ballantine Books.

Sarrazin, P.G., Tessier, D.P., Pelletier, L.G., Trouilloud, D.O., \& Chanal, J.P. (2006). Effects of teachers' expectations about students' motivation on teachers' autonomy-supportive and controlling behaviors. International Journal of Sport and Exercise Psychology, 4, 283-301.

Sarrazin, P., Trouilloud, D., Tessier, D., Chanal, J., \& Bois, J. (2005). Teacher's expectations about students' motivation and his/her differential treatments: A study in physical education classes. European Review of Applied Psychology, 55, 111-120. doi:10.1016/j. erap.2004.06.005

Smith, R., \& Smoll, F. (2006). Enhancing coach-athlete relationships: Cognitive-behavioral principles and procedures. In J. Donsil (Ed.), The sport psychologist's handbook (pp. 19-37). New York: John Wiley \& Sons.

Smith, B., Sparkes, A.C., Phoenix, C., \& Kirkby, J. (2012). Qualitative research in physical therapy: A critical discussion on mixed-method research. The Physical Therapy Review, 17, 374-381.

Soenens, B., Vansteenkiste, M., Sierens, E., Dochy, F., \& Goossens, L. (2012). Psychologically controlling teaching: Examining outcomes, antecedents, and mediators. Journal of Educational Psychology, 104, 108-120. doi:10.1037/a0025742

Sparkes, A.C., \& Smith, B. (2009). Judging the quality of qualitative inquiry: Criteriology and relativism in action. Psychology of Sport and Exercise, 10, 491-497. doi:10.1016/j. psychsport.2009.02.006

Stebbings, J., Taylor, I.M., \& Spray, C.M. (2011). Antecedents of perceived coach autonomy supportive and controlling behaviors: Coach psychological need satisfaction and well-being. Journal of Sport \& Exercise Psychology, 33, 255-272. PubMed doi:10.1123/jsep.33.2.255

Teixeira, P.J., Carraca, E.V., Markland, D., Silva, M.N., \& Ryan, R.M. (2012). Exercise, physical activity, and self-determination theory: A systematic review. The International Journal of Behavioral Nutrition and Physical Activity, 9, 78-107. PubMed doi:10.1186/1479-5868-9-78 
Tracy, S.J. (2010). Qualitative quality: Eight "big-tent" criteria for excellent qualitative research. Qualitative Inquiry, 16, 837-851. doi:10.1177/1077800410383121

Vallerand, R.J., \& Losier, G.F. (1999). An integrative analysis of intrinsic and extrinsic motivation in sport. Journal of Applied Sport Psychology, 11, 142-169. doi:10.1080/10413209908402956

van der Mars, H. (1989). Observer reliability: Issues and procedures. In P.W. Darst, D.B. Zakrajsek, \& V.H. Mancini (Eds.), Analyzing Physical Education and sport instruction (2nd ed., pp. 53-80). Champaign, IL: Human Kinetics.

Webster, C.A., Hunt, K., \& LaFleche, M. (2013). Are winning coaches more autonomysupportive? Examining the context of varsity boys' soccer. Journal of Sport Behavior, 36, 209-232.

Weed, M. (2009). Research quality considerations for grounded theory research in sport \& exercise psychology. Psychology of Sport and Exercise, 10, 502-510. doi:10.1016/j. psychsport.2009.02.007 